\title{
ARTICLE
}

Epidemiology

\section{Syncope as a sign of occult cancers: a population-based cohort study}

\author{
Mads Okkels Birk Lorenzen (D) ${ }^{1}$, Dóra Körmendiné Farkas ${ }^{1}$, Kasper Adelborg ${ }^{1,2}$, Jens Sundbøll ${ }^{1}$ and Henrik Toft Sørensen ${ }^{1}$
}

BACKGROUND: We examined if syncope was a marker of an occult cancer by comparing the risk in patients with a syncope episode with that of the general population.

METHODS: Using Danish population-based medical registries, we identified all patients diagnosed with syncope during 1994-2013 and followed them until a cancer diagnosis, emigration, death or end of follow-up, whichever came first. We computed cumulative risks and standardised incidence ratios (SIR) with $95 \%$ confidence intervals (CI).

RESULTS: Among 208,361 patients with syncope, 20,278 subsequent cancers were observed. The 6-month cumulative risk of any cancer was $1.2 \%$, increasing to $17.9 \%$ for 1-20 years of follow-up. The highest cumulative risks after 6 months of follow-up were lung cancer $(0.2 \%)$, colorectal cancer $(0.2 \%)$, prostate cancer $(0.1 \%)$ and brain cancer $(0.1 \%)$. The 6 -month SIR were $2.7(95 \% \mathrm{Cl}$ : 2.4-3.0) for lung cancer, 2.0 (95\% Cl: 1.8-2.2) for colorectal cancer, 1.7 (95\% Cl: 1.5-1.9) for prostate cancer and 10.0 (95\% Cl: 8.6-11.4) for brain cancer.

CONCLUSIONS: Syncope was a weak marker of an occult cancer. In short-term the highest cumulative risks were observed for lung, colorectal, prostate and brain cancers. An aggressive search for occult cancer in a patient with syncope is probably not warranted.

British Journal of Cancer (2020) 122:595-600; https://doi.org/10.1038/s41416-019-0692-2

\section{BACKGROUND}

Syncope is defined as a sudden loss of consciousness of short duration, with an inability to maintain postural tone, and spontaneous complete recovery. ${ }^{1,2}$ Episodes occur frequently, accounting for $\sim 1 \%$ of all referrals to emergency departments. ${ }^{1}$ The lifetime cumulative risk of syncope is approximately $35 \%{ }^{3}$ Clinically, the condition is categorised on the basis of underlying pathophysiology, i.e. reflex-mediated, orthostatic hypotension or cardiac syncope. ${ }^{1}$ Whether syncope may be the presenting sign of an occult cancer is largely unknown. Only a few case reports are available. ${ }^{4-17}$ Thus, firm epidemiological evidence on the association between syncope and cancer is lacking.

Syncope can occur due to stimulation of the parasympathetic nervous system or carotid sinus by direct neoplastic infiltration., ${ }^{7,-16}$ Syncope also can be the first sign of intracranial tumours due to involvement of autonomic cardiovascular control areas. ${ }^{4,18-20}$ Additionally, a recent multicentre study showed that pulmonary embolism was identified in nearly one of every six patients hospitalised for a first episode of syncope, ${ }^{21}$ and pulmonary embolism, in turn, is established as a marker for occult cancer. ${ }^{22,23}$ Therefore, it is possible that syncope may be associated with an underlying undiagnosed cancer. Electrolyte imbalance and paraneoplastic phenomena also may induce syncope, as observed in patients with pheochromocytoma, ${ }^{24}$ mastocytosis, ${ }^{25,26}$ and carcinoid syndrome. $^{27}$

To study these issues in detail, we examined overall risk of cancer and risk of site-specific cancers in a large cohort of syncope patients, and we compared their cancer risk with that of the general population.

\section{METHODS}

Design and setting

We conducted a nationwide population-based cohort study in Denmark between 1 January 1994 and 30 November 2013. The Danish national health system provides tax-supported healthcare to all residents of Denmark, ensuring equal access to general practice and hospital care. ${ }^{28}$ Contacts with the healthcare system are recorded in national databases. ${ }^{29,30}$ Linkage among databases is possible through a unique ten-digit personal identification number assigned to each Danish resident. ${ }^{29}$

\section{Patients with syncope}

We used the Danish National Patient Registry (DNPR) to identify all patients with a first-time inpatient, outpatient or emergency room diagnosis of syncope. We excluded patients with a history of a cancer diagnosis recorded in the Danish Cancer Registry (DCR). The DNPR contains data on all inpatient admissions to nonpsychiatric hospitals since 1977 and on hospital outpatient and emergency room contacts since 1995. Information recorded in the DNPR includes admission and discharge dates, and one primary and up to nineteen secondary discharge diagnoses coded according to the International Classification of Diseases (ICD) Tenth Revision since $1994 .{ }^{30}$ The syncope diagnosis has previously 
been reported with a positive predictive value of $95 \%$, and thus diagnostic misclassification of the exposure is likely negligible. ${ }^{31}$

Cancer

To obtain information on incident cancers diagnosed after a syncope episode, we linked our patient cohort to the DCR. ${ }^{32}$ This registry contains detailed information on cancers diagnosed in Denmark since 1943, with information on morphology, histology and cancer stage at diagnosis. ${ }^{33}$ We categorised the cancers according to recommendations from the Danish National Board of Health $^{34}$ (Supplementary Table 1).

\section{Comorbidity}

Information on several comorbidities was obtained from the DNPR. These included diagnoses of head trauma, diabetes mellitus, myocardial infarction, heart failure, atrial fibrillation, valvular heart disease, chronic lower respiratory diseases, chronic kidney disease, obesity, alcoholism-related disorders, epilepsy, narcolepsy and cataplexy, stroke, angina pectoris, hypertension, anaemia, lower urinary tract obstruction and venous thromboembolism. Changes in vital and migration status were ascertained from the Danish Civil Registration System, which is electronically updated on a daily basis. ${ }^{29}$ All ICD codes used in the study are provided in Supplementary Table 1.

\section{Statistical analyses}

We followed the patients from their syncope episode (hospital contact date) until a cancer diagnosis, death, emigration, or 30 November 2013, whichever came first. We tabulated characteristics of the syncope cohort and calculated cumulative risks (\%) of a cancer diagnosis during 0-6 months, >6-12 months and 1-20 years following a syncope episode, treating death as a competing risk. ${ }^{35,36}$ Assuming that the observed number of cancers followed a Poisson distribution, we calculated relative risks by comparing the observed number to the expected number of cancers (based on national incidence rates, by sex, age and calendar year, in 1 year intervals) to obtain a standardised incidence rate (SIR) with 95\% confidence intervals (Cls). The SIR analysis also takes into account the competing risk of death, as individuals are censored when they die and because the national cancer incidence rates are based exclusively on individuals at risk of cancer, censoring individuals who die or emigrate. Exact $95 \% \mathrm{Cls}$ were used when the observed number of cancers was less than ten. ${ }^{35,37}$ We stratified the main analyses (SIRs) by follow-up time (0-6 months, $>6-12$ months, $>12$ months and $0-20$ years), age (0-29 years, 30-49 years, 50-69 years and $>70$ years), calendar period (1994-1998, 1999-2003, 2004-2008 and 2009-2013) and sex. In addition, we stratified the analyses by presence or absence of the individual comorbidities presented in Table 1 (except for narcolepsy and cataplexy, due to their low prevalence). This analysis was performed only for the four most common cancers to retain statistical precision of the estimates (Supplementary Table 2-5). We calculated the number of patients needed to be screened to find 1 excess cancer as the reciprocal of excess risk, assuming that the cancer diagnosed within 6 months after the syncope diagnosis was already present at the syncope diagnosis.

All statistical analyses were conducted using SAS, version 9.4 (SAS Institute, Cary, NC). The study was approved by the Danish Data Protection Agency (record number: 1-16-02-1-08). In Denmark, registry-based research does not require permission from an ethics committee or informed consent from patients.

\section{RESULTS}

We identified 208,361 patients with a first-time episode of syncope. Among these patients, $47 \%$ were male, $88 \%$ had syncope as their primary reason for the index hospital contact. In the syncope cohort, $50 \%$ were inpatients, $13 \%$ outpatients and
Table 1. Characteristics of the syncope cohort, Denmark, 1994-2013.

\begin{tabular}{|c|c|}
\hline Total number & $208,361(100)$ \\
\hline \multicolumn{2}{|l|}{ Sex } \\
\hline Male & $97,135(47)$ \\
\hline Female & $111,226(53)$ \\
\hline \multicolumn{2}{|l|}{ Type of contact } \\
\hline Inpatients & $104,420(50)$ \\
\hline Outpatients & $27,427(13)$ \\
\hline Emergency patients & $76,514(37)$ \\
\hline \multicolumn{2}{|l|}{ Type of diagnosis } \\
\hline Primary diagnosis ${ }^{a}$ & $182,869(88)$ \\
\hline Secondary diagnosis & $25,492(12)$ \\
\hline Median age, years (25th-75th percentiles) & $57(32-74)$ \\
\hline \multicolumn{2}{|l|}{ Age group, years } \\
\hline $0-29$ years & $48,143(23)$ \\
\hline $30-49$ years & $38,257(18)$ \\
\hline $50-69$ years & $56,731(27)$ \\
\hline$\geq 70$ years & $65,230(31)$ \\
\hline \multicolumn{2}{|l|}{ Calendar period } \\
\hline 1994-1998 & $39,622(19)$ \\
\hline 1999-2003 & $51,815(25)$ \\
\hline 2004-2008 & $56,501(27)$ \\
\hline 2009-2013 & $60,423(29)$ \\
\hline Median follow-up time, years (25th-75th percentiles) & $56(2-10)$ \\
\hline \multicolumn{2}{|l|}{ Comorbidities } \\
\hline Head trauma & $58,958(28)$ \\
\hline Diabetes mellitus & $11,484(6)$ \\
\hline Myocardial infarction & $12,869(6)$ \\
\hline Heart failure & $11,400(6)$ \\
\hline Atrial fibrillation & $17,637(8)$ \\
\hline Valvular heart disease & $4903(2)$ \\
\hline Chronic lower respiratory diseases & $15,805(8)$ \\
\hline Chronic kidney disease & $3961(2)$ \\
\hline Obesity & $6457(3)$ \\
\hline Alcoholism-related disorders & $10,309(5)$ \\
\hline Epilepsy & $10,093(5)$ \\
\hline Narcolepsy and cataplexy & $48(0)$ \\
\hline Stroke & $14,829(7)$ \\
\hline Angina pectoris & $18,287(9)$ \\
\hline Hypertension & $26,771(13)$ \\
\hline Anemia & $2171(1)$ \\
\hline Lower urinary tract obstruction & $5387(3)$ \\
\hline Venous thromboembolism & $4986(2)$ \\
\hline
\end{tabular}

Patients also can be assigned one or more appropriate secondary diagnoses Data are numbers (\%)

aPrimary diagnosis refer to the primary reason for a hospital contact

$37 \%$ emergency room contacts. The median age was 57 years and median follow-up time was 5.6 years. Head trauma, cardiovascular disease (hypertension, atrial fibrillation and angina pectoris) and chronic lower respiratory diseases were the most frequent comorbidities (Table 1).

We observed 20,278 cancers during 20 years of follow-up. The cumulative risk of any cancer diagnosis after 6 months of followup was $1.2 \%$, increasing to $17.9 \%$ for $1-20$ years of follow-up (Table 2). The 6-month cumulative risk of cancer was mainly driven 
Syncope as a sign of occult cancers: a population-based cohort study MOB Lorenzen et al.

Table 2. Cumulative risks of cancer among patients with syncope by follow-up time, treating death as competing risk.

\begin{tabular}{|c|c|c|c|}
\hline Type of cancer & $0-6$ months & $>6-12$ months & $1-20$ years \\
\hline All & $1.2(1.2-1.3)$ & $0.7(0.7-0.7)$ & $17.9(17.3-18.3)$ \\
\hline \multicolumn{4}{|l|}{ Intracranial tumours } \\
\hline Meninges & $0.1(0.0-0.1)$ & $<0.1^{d}$ & $0.2(0.1-0.2)$ \\
\hline Brain & $0.1(0.1-0.1)$ & $<0.1^{d}$ & $0.4(0.3-0.5)$ \\
\hline \multicolumn{4}{|c|}{ Supradiaphragmatic tumours } \\
\hline Pharynx ${ }^{a}$ & $<0.1^{d}$ & $<0.1^{d}$ & $0.2(0.2-0.3)$ \\
\hline Lung & $0.2(0.2-0.2)$ & $0.1(0.1-0.1)$ & $1.8(1.7-2.0)$ \\
\hline Tongue & $<0.1^{d}$ & $<0.1^{d}$ & $0.1(0.0-0.1)$ \\
\hline Oral cavity & $<0.1^{d}$ & $<0.1^{d}$ & $0.1(0.1-0.2)$ \\
\hline Breast & $0.1(0.1-0.1)$ & $0.1(0.1-0.1)$ & $1.5(1.4-1.7)$ \\
\hline \multicolumn{4}{|c|}{ Infradiaphragmatic tumours } \\
\hline Liver & $<0.1^{d}$ & $<0.1^{d}$ & $0.3(0.2-0.4)$ \\
\hline Stomach & $<0.1^{d}$ & $<0.1^{d}$ & $0.2(0.2-0.3)$ \\
\hline Kidney & $<0.1^{d}$ & $<0.1^{d}$ & $0.2(0.2-0.3)$ \\
\hline Colorectal $^{\mathrm{b}}$ & $0.2(0.1-0.8)$ & $0.1(0.1-0.1)$ & $1.9(1.7-2.0)$ \\
\hline Oesophagus & $<0.1^{d}$ & $<0.1^{d}$ & $0.2(0.2-0.3)$ \\
\hline Prostate & $0.1(0.1-0.1)$ & $0.1(0.1-0.1)$ & $1.8(1.7-2.0)$ \\
\hline Pancreas & $<0.1^{d}$ & $<0.1^{d}$ & $0.4(0.3-0.4)$ \\
\hline Ovary & $<0.1^{d}$ & $<0.1^{d}$ & $0.2(0.1-0.2)$ \\
\hline Urinary bladder & $0.1(0.0-0.1)$ & $<0.1^{d}$ & $0.9(0.8-1.0)$ \\
\hline \multicolumn{4}{|c|}{ Haematology malignancies } \\
\hline $\begin{array}{l}\text { Non-Hodgkin } \\
\text { lymphoma incl. } \\
\text { multiple myeloma }\end{array}$ & $0.1(0.0-0.1)$ & $<0.1^{d}$ & $0.6(0.5-0.7)$ \\
\hline Leukaemiac $^{c}$ & $<0.1^{d}$ & $<0.1^{d}$ & $0.3(0.2-0.3)$ \\
\hline
\end{tabular}

Data are percentages with $95 \%$ confidence intervals

aPharyngeal cancers include cancers in the nasal part of the pharynx, pharyngeal tonsil, the pharyngeal cavity, and other parts of the pharynx (unspecified, Waldeyer's ring, and overlapping lesions of the lip, oral cavity, and pharynx)

${ }^{b}$ Colorectal cancer includes cancers of the rectum, caecum, anus, appendix, ascending colon hepatic flexure, transverse colon, splenic flexure, descending colon, sigmoid colon, and colon unspecified

'Leukaemia includes: monocytic leukaemia, acute myeloid leukaemia (acute myeloid leukaemia with multilineage dysplasia and myeloid leukaemia, unspecified), and other leukaemias of specified cell type. Lymphoid leukaemia: acute leukaemias, chronic lymphocytic leukaemia of B-cell type, prolymphocytic leukaemia of B-cell type, hairy-cell leukaemia, adult T-cell lymphoma/leukaemia, prolymphocytic leukaemia of T-cell type, other lymphoid leukaemia, mature B-cell leukaemia Burkitt-type, and lymphoid leukaemia, unspecified

${ }^{\mathrm{d} C}$ Cumulative risk below $0.1 \%$ due to low number of outcomes

by lung cancer $(0.2 \%)$, colorectal cancer $(0.2 \%)$, prostate cancer $(0.1 \%)$ and brain cancer $(0.1 \%)$. The 6 -month cumulative risks were low for haematological malignancies (below $0.1 \%$ for all groups of cancers) (Table 2).

The 6-month SIR for any cancer was 2.0 (95\% Cl: 1.8-2.0), while the >6-12 month and >12-month SIRs were 1.1 (95\% Cl: 1.0-1.1) and 1.0 (95\% Cl: $1.0-1.0)$, respectively (Table 3$)$. The overall cancer SIR was slightly higher during 2009-2013 than during 1994-1998. It was also higher among patients aged $30-49$ years $[S I R=1.2$ (95\% Cl: 1.1-1.2)] than among other age groups. In addition, the SIR was slightly higher among men $[\mathrm{SIR}=1.1$ (95\% Cl: 1.1-1.2)] than among women $[\mathrm{SIR}=1.1(95 \% \mathrm{Cl}$ : 1.0-1.1)] (Table 3). The 6month SIRs were 2.7 (95\% Cl: 2.4-3.0) for lung cancer, 2.0 (95\% Cl: 1.8-2.2) for colorectal cancer, $1.7(95 \% \mathrm{Cl}$ : 1.5-1.9) for prostate cancer, and 10.0 (95\% Cl: 8.6-11.4) for brain cancer (Table 4).
Table 3. Observed vs. expected cancers in the syncope cohort and standardised incidence ratios (SIRs) in analyses stratified by age, calendar period, and sex.

\begin{tabular}{lll}
\hline & Observed/expected & SIR (95\% confidence interval) \\
\hline Any cancer & & \\
$\quad 0-6$ months & $2541 / 1333$ & $2.0(1.8-2.0)$ \\
$>6-12$ months & $1328 / 1245$ & $1.1(1.0-1.1)$ \\
$>12$ months & $16,409 / 16,029$ & $1.0(1.0-1.0)$ \\
$0-20$ years & $20,278 / 18,607$ & $1.1(1.1-1.1)$ \\
Age groups, years & & \\
$0-29$ & $384 / 330$ & $1.2(1.1-1.3)$ \\
$30-49$ & $1844 / 1573$ & $1.2(1.1-1.2)$ \\
$50-69$ & $8356 / 7570$ & $1.1(1.1-1.1)$ \\
$70+$ & $9694 / 9134$ & $1.1(1.0-1.1)$ \\
Calendar period & & $1.1(1.0-1.1)$ \\
$1994-1998$ & $5936 / 5605$ & $1.1(1.0-1.1)$ \\
$1999-2003$ & $6686 / 6253$ & $1.1(1.1-1.1)$ \\
$2004-2008$ & $5315 / 4879$ & $1.3(1.2-1.3)$ \\
$2009-2013$ & $2341 / 1870$ & $1.1(1.0-1.1)$ \\
Sex & & $1.1(1.1-1.2)$ \\
Female & $9157 / 8727$ & \\
Male & $11,121 / 9880$ &
\end{tabular}

In stratified analyses we found that the SIR of cancer (except breast cancer) was higher for those with anaemia than those without anaemia (Supplementary Table 2-5). For example, the 6month SIR of colorectal cancer was 3.4 (95\% Cl: 1.5-6.7) for patients with anaemia, while it was 2.0 (95\% Cl: 1.8-2.2) for those without anaemia (Supplementary Table 3). For syncope patients with and without lower urinary tract obstruction, the cancer SIRs were fairly comparable, although the 6-month SIR of prostate cancer was 3.3 (95\% Cl: 2.3-4.6) for patients with lower urinary tract obstruction and $1.5(95 \% \mathrm{Cl}: 1.3-1.8)$ for those without (Supplementary Table 5). The cancer SIRs were broadly similar for patients with and without venous thromboembolism (Supplementary Table 2-5).

During 6 months of follow-up, we found 1208 excess cancers (2541 observed-1333 expected) (Table 3 ). The number of patients needed to be screened among the syncope cohort to find 1 excess cancer was 172 (208,361 total/1208 excess cancers).

\section{DISCUSSION}

In this large population-based cohort study, syncope was a weak marker of an occult cancer. The cumulative risks were low and after 6 months of follow-up, it was mostly elevated for lung, colorectal, prostate and brain cancers.

The association between syncope as marker of occult cancer has been sparsely documented in the literature. Several case reports found that syncope was the presenting symptom of lung cancer $^{10-12}$ and brain cancer. ${ }^{3-5}$ In contrast, such reports were not found for colorectal or prostate cancers. This may indicate that cancer-induced syncope is more frequently due to undiagnosed lung cancer than colorectal or prostate cancer. Our findings support this notion, i.e., the most frequent occult cancers found in the syncope cohort were cancers of the lung, particularly in the short-term. Case reports describing syncope as the initial symptom of a brain tumour also are in line with our findings. ${ }^{3-5}$ Although several case reports described syncope as a symptom of head and neck cancer $r^{7,13-16}$ or an undiagnosed haematological malignancy, ${ }^{38-41}$ our findings suggest that the cumulative risks were low for these conditions. 
Table 4. Risk of site-specific cancers after syncope, by follow-up period. ${ }^{a}$

\begin{tabular}{|c|c|c|c|c|c|c|c|c|}
\hline \multirow[t]{2}{*}{ Site } & \multicolumn{2}{|l|}{$0-6$ months } & \multicolumn{2}{|c|}{$>6-12$ months } & \multicolumn{2}{|l|}{$>12$ months } & \multicolumn{2}{|l|}{$0-20$ years } \\
\hline & $\begin{array}{l}\text { Observed/ } \\
\text { expected }\end{array}$ & SIR $(95 \% \mathrm{CI})$ & $\begin{array}{l}\text { Observed/ } \\
\text { expected }\end{array}$ & SIR $(95 \% \mathrm{CI})$ & $\begin{array}{l}\text { Observed/ } \\
\text { expected }\end{array}$ & $\operatorname{SIR}(95 \% \mathrm{CI})$ & $\begin{array}{l}\text { Observed/ } \\
\text { expected }\end{array}$ & $\operatorname{SIR}(95 \% \mathrm{CI})$ \\
\hline \multicolumn{9}{|l|}{ Intracranial tumours } \\
\hline Meninges & $93 / 8$ & $11.4(9.2-13.4)$ & $19 / 8$ & $2.5(1.5-3.9)$ & $157 / 106$ & $1.5(1.3-1.8)$ & $269 / 121$ & $2.2(2.0-2.5)$ \\
\hline Brain & $231 / 23$ & $9.99(8.6-11.4)$ & $46 / 22$ & $2.1(1.6-2.8)$ & $338 / 284$ & $1.2(1.2-1.3)$ & $615 / 329$ & $1.9(1.7-2.0)$ \\
\hline \multicolumn{9}{|c|}{ Supradiaphragmatic tumours } \\
\hline Pharynx ${ }^{b}$ & $17 / 7$ & $2.3(1.4-3.7)$ & $12 / 7$ & $1.8(0.9-3.1)$ & $182 / 96$ & $1.9(1.6-2.2)$ & $211 / 110$ & $1.9(1.7-2.2)$ \\
\hline Lung & $366 / 135$ & $2.7(2.4-3.0)$ & $134 / 125$ & $1.1(0.9-1.3)$ & $1655 / 1541$ & $1.1(1.0-1.1)$ & $2155 / 1802$ & $1.2(1.2-1.3)$ \\
\hline Tongue & $9 / 3$ & $2.6(1.2-4.9)$ & $7 / 3$ & $2.2(0.9-4.4)$ & $56 / 44$ & $1.3(1.0-1.7)$ & $69 / 48$ & $1.4(1.1-1.8)$ \\
\hline Oral cavity & $13 / 6$ & $2.1(1.1-3.7)$ & $13 / 6$ & $2.3(1.2-3.9)$ & $116 / 71$ & $1.6(1.3-2.0)$ & $142 / 83$ & $1.7(1.4-2.0)$ \\
\hline Breast & $140 / 114$ & $1.2(1.0-1.5)$ & $110 / 108$ & $1.0(0.8-1.2)$ & $1407 / 1424$ & $1.0(0.9-1.0)$ & $1657 / 1646$ & $1.0(1.0-1.1)$ \\
\hline \multicolumn{9}{|c|}{ Infradiaphragmatic tumours } \\
\hline Liver & $41 / 11$ & $3.8(2.8-5.2)$ & $16 / 10$ & $1.6(0.9-2.6)$ & $162 / 124$ & $1.3(1.1-1.5)$ & $219 / 145$ & $1.5(1.3-1.7)$ \\
\hline Stomach & $60 / 20$ & $2.9(2.6-3.8)$ & $29 / 19$ & $1.5(1.0-2.2)$ & $212 / 220$ & $1.0(0.8-1.1)$ & $301 / 259$ & $1.2(1.0-1.3)$ \\
\hline Kidney & $49 / 19$ & $2.6(1.9-3.5)$ & $24 / 17$ & $1.4(0.9-2.1)$ & $229 / 219$ & $1.0(0.9-1.2)$ & $302 / 256$ & $1.2(1.1-1.3)$ \\
\hline Colorectal $^{\mathrm{C}}$ & $308 / 155$ & $2.0(1.8-2.2)$ & $149 / 145$ & $1.0(0.9-1.2)$ & $1812 / 1765$ & $1.0(1.0-1.1)$ & $2269 / 2065$ & $1.1(1.1-1.6)$ \\
\hline Oesophagus & $27 / 15$ & $1.8(1.2-2.7)$ & $18 / 14$ & $1.3(0.8-2.1)$ & $220 / 169$ & $1.3(1.1-1.5)$ & $265 / 198$ & $1.3(1.2-1.5)$ \\
\hline Prostate & $228 / 135$ & $1.7(1.5-1.9)$ & $120 / 126$ & $1.0(0.8-1.1)$ & $1610 / 1649$ & $1.0(0.9-1.0)$ & 1958/1910 & $1.0(1.0-1.1)$ \\
\hline Pancreas & $48 / 31$ & $1.6(1.1-2.1)$ & $17 / 29$ & $0.6(0.3-0.9)$ & $375 / 361$ & $1.0(0.9-1.2)$ & $440 / 421$ & $1.0(1.0-1.2)$ \\
\hline Urinary bladder & $93 / 69$ & $1.4(1.1-1.7)$ & $79 / 64$ & $1.24(1.0-1.6)$ & 787/748 & $1.1(1.0-1.1)$ & 959/879 & $1.1(1.0-1.2)$ \\
\hline \multicolumn{9}{|l|}{ Haematology malignancies } \\
\hline $\begin{array}{l}\text { Non-Hodgkin } \\
\text { lymphoma incl. } \\
\text { multiple myeloma }\end{array}$ & $100 / 42$ & $2.4(2.0-2.9)$ & $40 / 39$ & $1.0(0.7-1.4)$ & $516 / 495$ & $1.0(1.0-1.1)$ & $656 / 576$ & $1.14(1.05-1.23$ \\
\hline Leukaemia $^{d}$ & $54 / 28$ & $1.9(1.5-2.5)$ & $30 / 26$ & $1.2(0.8-1.7)$ & $275 / 317$ & $0.9(0.8-1.0)$ & $359 / 371$ & $1.0(0.9-1.1)$ \\
\hline \multicolumn{9}{|c|}{ Cancers with no associations } \\
\hline Ovary & $22 / 16$ & $1.3(0.8-2.0)$ & $14 / 15$ & $0.9(0.5-1.5)$ & $171 / 187$ & $0.9(0.8-1.1)$ & $207 / 218$ & $1.0(0.8-1.1)$ \\
\hline Melanoma & $41 / 33$ & $1.3(0.90-1.7)$ & $37 / 31$ & $1.2(0.8-1.7)$ & $438 / 447$ & $1.0(0.9-1.1)$ & $516 / 510$ & $1.0(0.9-1.1)$ \\
\hline $\begin{array}{l}\text { Basal cell carcinoma } \\
\text { of the skin }\end{array}$ & $258 / 262$ & $1.0(0.9-1.1)$ & $228 / 245$ & $0.9(0.8-1.1)$ & $3271 / 3412$ & $1.0(0.9-1.0)$ & $3757 / 3921$ & $1.0(0.9-1.0)$ \\
\hline $\begin{array}{l}{ }^{\mathrm{a}} \text { Only cancer sites with to } \\
\text { bPharynx includes cancers } \\
\text { and overlapping lesions o } \\
{ }^{\mathrm{c} C o l o r e c t a l ~ c a n c e r ~ i n c l u d e ~} \\
\text { colon, sigmoid colon, and } \\
\text { d Leukaemia includes: mo } \\
\text { unspecified), and other } \\
\text { prolymphocytic leukaemi }\end{array}$ & $\begin{array}{l}\text { s in the nasa } \\
\text { of the lip, or } \\
\text { es cancers ir } \\
\text { colon unsp } \\
\text { onocytic leu }\end{array}$ & $\begin{array}{l}\text { with } 95 \% \text { co } \\
\text { comes above } \\
\text { of the pharynx } \\
\text { ty, and pharyn } \\
\text { ectum, caecur } \\
\text { a, acute myel }\end{array}$ & appe & $\begin{array}{l}\text { he pharyn } \\
\text { scending } \\
\text { e myeloid }\end{array}$ & $\begin{array}{l}\text { avity, and } \\
\text { hepatic } f \\
\text { aemia w }\end{array}$ & $\begin{array}{l}\text { arts of ph } \\
\text { ansverse } \\
\text { lineage }\end{array}$ & $\begin{array}{l}\text { nx (unspeci } \\
\text { lon, splenic } \\
\text { plasia and } \\
\text { ytic leukae }\end{array}$ & $\begin{array}{l}\text { Waldeyer's ring, } \\
\text { xure, descending } \\
\text { eloid leukaemia, }\end{array}$ \\
\hline
\end{tabular}

Cancer might be associated with syncope for several pathophysiological reasons. Lung cancer may cause syncope due to cerebral hypoperfusion or brain metastases. Cerebral hypoperfusion may be induced by compression of blood vessels by tumours, reducing blood flow to the heart or brain, or by direct infiltration of the vagus and glossopharyngeal nerves. ${ }^{10}$ Although the mechanisms are not well understood, brain metastases from lung cancer may involve areas responsible for cardiovascular control (brainstem, thalamus, hypothalamus, insular cortex or amygdala) and thus cause syncope. ${ }^{4,42,43}$ This is supported by case reports of frontal and temporal lobe tumours, as well as craniocervical junction tumours, which provide the best explanation for bradycardia and/or cardiac asystole and subsequent syncope. ${ }^{18-20}$ It is also possible that invasion or compression of vessels by a tumour reduce blood flow to the heart and brain, inducing cerebral hypotension. However, only one case report on infradiaphragmatic tumours in the form of renal cell carcinoma has supported this explanation. ${ }^{8}$ Another possibility is metastases from a colorectal cancer to the lung and brain; however, this is not a frequent complication. ${ }^{44,45}$ Furthermore, anaemia may play a role in inducing syncope, ${ }^{46}$ and is often a complication to cancer. ${ }^{47}$ This notion was supported by our stratified analyses, although the prevalence of anaemia likely is underestimated in our population. This misclassification implies that the impact of anaemia might be even higher than observed in our data. Another well-known syncope-inducing mechanism is micturition. ${ }^{48}$ It is thought that patients with lower urinary tract obstruction might experience micturition syncope. ${ }^{49}$ Venous thromboembolism is also a well-known complication to cancer, and can also be a cause of syncope. ${ }^{50,51}$ However, in our data the cancer SIRs were fairly similar for those with and without venous thromboembolism, suggesting that venous thromboembolism 
may play a minor role only in the association between syncope and cancer.

As documented in our analyses, syncope may be the first sign of some cancers. Occult cancer diagnosed at the short-term followup following syncope likely represent aggressive and fast-growing tumours (i.e. lung cancer and colorectal), or slow-growing tumours that have gradually become large, until a certain point, where they will facilitate a syncope episode. As discussed previously it could involve e.g. the lower urinary system, compression of blood vessels to the heart and brain, or a slowly evolving anaemia.

At long-term follow-up, the predominant cancers are most likely slow-growing tumours (e.g. carcinoid tumours) that have been present for years without noticeable symptoms. At one point, they may hemodynamically destabilise the patient and induce a syncope.

The main strength of our study is its nationwide populationbased cohort design within a setting of free and equal access to healthcare service, which limits selection and referral biases. ${ }^{29}$ As well, coverage of cancer diagnoses is highly complete in the Danish Cancer Registry. ${ }^{33}$ Our study also has several potential limitations. Heightened diagnostic effort may explain in part the short-term cancer risk. However, if diagnostic bias was prominent, we would expect a drop in overall SIR estimates (to below 1) after 6 months as a compensatory deficit. As this pattern not was observed in our analyses, heightened diagnostic efforts are unlikely to explain our findings. We lacked clinical detail and the exact benefit of searching for cancer in a patient with a syncope is therefore difficult to assess. In our cohort, most of the cancers that were found during the first year of follow-up were probably present at the time of the syncope. The detection of some of these cancers would have required an extensive diagnostic workup, and it is unclear whether early diagnosis would have changed the outcome. For several of the types of cancer, such as brain cancer, early detection may not necessarily change the prognosis. Other cancers might be detected by simple methods. In the group we studied, 208,361 persons would have had to be screened for the 1208 excess cancers to be found during the first 6 months of follow-up. It should be noted that we in this calculation assumed a screening sensitivity of $100 \%$, which is rarely the case. In addition, the screening sensitivity may differ among different cancers types. It is also unknown if formal screening for cancer symptoms among syncope patients will benefit their prognosis. Therefore, extensive cancer screening of patients with syncope does not seem to be cost effective.

\section{CONCLUSION}

In this population-based study, an episode of syncope was a weak marker of an occult cancer diagnosed within the following 6 months, mainly driven by lung, colorectal, prostate and brain cancers.

\section{ACKNOWLEDGEMENTS}

None.

\section{AUTHOR CONTRIBUTIONS}

M.O.B.L. wrote the manuscript with support from K.A. and J.S. H.T.S conceived the presented idea, designed the study, and supervised the findings. D.K.F. did the statistical analysis and modelling. All authors discussed the results and contributed to the final manuscript.

\section{ADDITIONAL INFORMATION}

Ethics approval and consent to participate In Denmark, registry-based research does not require permission from an ethics committee or informed consent from patients.
Data availability Danish law does not allow researchers to share raw data or datasets which include individual-level datapoints from the registries with third parties. Data can be accessed by researchers through application to the Health Data Authority (contact:forskerservice@sundhedsdata.dk). However, a formal affiliation or collaboration with a Danish research institution is required. Acquisition of data are only allowed after permission to handle data has been obtained from the Danish Data Protection Agency (contact: dt@datatilsynet.dk).

Competing interests M.O.B.L., K.A., J.S. and D.K.F. report no potential conflict of interest, including no financial interests. Professor Sørensen does not report receiving fees, honoraria, grants or consultancies.

Funding information This research received no specific grant from any funding agency in the public, commercial, or not-for-profit sectors. Department of Clinical Epidemiology is, however, involved in studies with funding from various companies as research grants to (and administered by) Aarhus University.

Supplementary information is available for this paper at https://doi.org/10.1038/ s41416-019-0692-2.

Note: This work is published under the standard license to publish agreement. After 12 months the work will become freely available and the license terms will switch to a Creative Commons Attribution 4.0 International (CC BY 4.0).

Publisher's note Springer Nature remains neutral with regard to jurisdictional claims in published maps and institutional affiliations.

\section{REFERENCES}

1. Task Force for the D, Management of $S$, European Society of $C$, European Heart Rhythm A, Heart Failure A, Heart Rhythm S. et al. Guidelines for the diagnosis and management of syncope (version 2009). Eur. Heart J. 30, 2631-2671 (2009).

2. Soteriades, E. S., Evans, J. C., Larson, M. G., Chen, M. H., Chen, L., Benjamin, E. J. et al. Incidence and prognosis of syncope. N. Engl. J. Med. 347, 878-885 (2002).

3. Ganzeboom, K. S., Mairuhu, G., Reitsma, J. B., Linzer, M., Wieling, W. \& van Dijk, N. Lifetime cumulative incidence of syncope in the general population: a study of 549 Dutch subjects aged 35-60 years. J. Cardiovasc. Electrophysiol. 17, 1172-1176 (2006).

4. Van der Sluijs, B. M., Renier, W. O. \& Kappelle, A. C. Brain tumour as a rare cause of cardiac syncope. J. Neuro-Oncol. 67, 241-244 (2004).

5. Syed, S. \& Westwood, A. J. Clinical reasoning: a 25-year-old man with headaches and collapse. Neurology 80, e211-e214 (2013).

6. Le, B. H. \& Truex, R. C. 29 year-old male with seizure and syncope. Intracerebral Langerhans cell histiocytosis. Brain Pathol. (Zur., Switz.). 23, 363-364 (2013).

7. Holmes, F. A., Glass, J. P., Ewer, M. S., Terjanian, T. \& Tetu, B. Syncope and hypotension due to carcinoma of the breast metastatic to the carotid sinus. Am. J. Med. 82, 1238-1242 (1987).

8. Osafo, N., Goel, K. \& Geske, J. An unusual cause of syncope while gardening. Eur. Heart J. 37, 1552 (2016).

9. Campagna, D., Amaradio, M. D., Battaglia, E., Demma, S., Russo, C. \& Polosa, R. An uncommon cause of syncope. Intern. Emerg. Med. 11, 425-429 (2016).

10. Jiang, X., Zhao, J., Bai, C., Xu, E., Chen, Z. \& Han, Y. Small-cell lung cancer with recurrent syncope as the initial symptom: A case report and literature review. Mol. Clin. Oncol. 5, 545-549 (2016).

11. Koga, T., Kaseda, S., Miyazaki, N., Kawazoe, N., Abe, I., Sadoshima, S. et al. Neurally mediated syncope induced by lung cancer-a case report. Angiology 51, 263-267 (2000).

12. Shimizu, K., Yoshii, Y., Watanabe, S., Hosoda, C., Takagi, M., Tominaga, T. et al. Neurally mediated syncope associated with small cell lung cancer: a case report and review. Intern. Med. (Tokyo, Jpn.). 50, 2367-2369 (2011).

13. Macdonald, D. R., Strong, E., Nielsen, S. \& Posner, J. B. Syncope from head and neck cancer. J. Neuro-Oncol. 1, 257-267 (1983).

14. Tang, Y., Wang, J. M. \& Huang, C. H. Syncope in nasopharyngeal carcinoma: report of three cases and review of the literature. Changgeng yi xue za zhi. 16, 59-65 (1993).

15. Pugliatti, P., Donato, R., Zito, C., Carerj, S. \& Patane, S. Cardioinhibitory vasovagal syncope in a cancer patient. Int. J. Cardiol. 174, e64-e65 (2014).

16. Wang, H., Wang, Y., Liu, H. \& Cai, L. Syncope associated with carotid sinus syndrome in an occult nasopharyngeal carcinoma. Int. J. Cardiol. 186, 236-238 (2015).

17. Babs Animashaun, I., Akinseye, O. A., Akinseye, L. I. \& Akinboboye, O. O. Right atrial myxoma and syncope. Am. J. Case Rep. 16, 645-647 (2015).

18. Kamil A., Ghazzay H. Bradycardia as the First Sign of Brain Tumor: A Case Report Journal of Medical Cases, ISSN 1923-4155 (2018). 
19. Park, K., Her, S., Lee, J., Yoon, H., Chin, J., Jeon, J., Park, Y., Do, K., Jung, Y. \& jin, S. Brain tumor is a rare cause of both bradycardia and seizure. Korean Soc. Circulation. 37, 449-452 (2007).

20. Champagne, P. O. \& Bojanowski, M. W. Craniocervical junction meningiomas without hydrocephalus presenting solely with syncope: Report of 2 Cases. World Neurosurg. 114, 161-164 (2018).

21. Prandoni, P., Lensing, A. W., Prins, M. H., Ciammaichella, M., Perlati, M., Mumoli, N. et al. Prevalence of pulmonary embolism among patients hospitalized for syncope. N. Engl. J. Med. 375, 1524-1531 (2016).

22. Monreal, M., Casals, A., Boix, J., Olazabal, A., Montserrat, E. \& Mundo, M. R. Occult cancer in patients with acute pulmonary embolism. A prospective study. Chest 103, 816-819 (1993).

23. Monreal, M., Lensing, A. W., Prins, M. H., Bonet, M., Fernandez-Llamazares, J., Muchart, J. et al. Screening for occult cancer in patients with acute deep vein thrombosis or pulmonary embolism. J. Thrombosis Haemost. 2, 876-881 (2004).

24. Roshan, J., George, O. K., Vineet, S., George, P. V. \& Jose, V. J. Torsade de pointes in a case of pheochromocytoma-an unusual presentation of an uncommon disease. Indian Heart J. 56, 248-249 (2004).

25. Shaffer, H. C., Parsons, D. J., Peden, D. B. \& Morrell, D. Recurrent syncope and anaphylaxis as presentation of systemic mastocytosis in a pediatric patient: case report and literature review. J. Am. Acad. Dermatol. 54(5 Suppl), S210-S213 (2006).

26. Bains, S. N. \& Hsieh, F. H. Current approaches to the diagnosis and treatment of systemic mastocytosis. Ann. Allergy, Asthma Immunol. Off. Publ. Am. Coll. Allergy, Asthma, Immunol. 104, 1-10 (2010). quiz -2, 41.

27. Suchard, J. R. Recurrent near-syncope with flushing. Acad. Emerg. Med. 4, 718-724 (1997).

28. Schmidt, M., Schmidt, S., Adelborg, K., Sundbøll, J., Laugesen, K., Ehrenstein, V. \& Sørensen, $\mathrm{H}$. The Danish Healthcare System and Epidemiological Research: from healthcare contacts to database records. Clin. Epidemiol. 11, 563-591 (2019).

29. Schmidt, M., Pedersen, L. \& Sorensen, H. T. The Danish Civil Registration System as a tool in epidemiology. Eur. J. Epidemiol. 29, 541-549 (2014).

30. Schmidt, M., Schmidt, S. A., Sandegaard, J. L., Ehrenstein, V., Pedersen, L. \& Sorensen, H. T. The Danish National Patient Registry: a review of content, data quality, and research potential. Clin. Epidemiol. 7, 449-490 (2015).

31. Ruwald, M. H., Hansen, M. L., Lamberts, M., Kristensen, S. L., Wissenberg, M., Olsen, A. M. et al. Accuracy of the ICD-10 discharge diagnosis for syncope. Europace 15, 595-600 (2013).

32. Gjerstorff, M. L. The Danish Cancer Registry. Scand. J. public health 39(7 Suppl), 42-45 (2011).

33. Storm, H. H., Michelsen, E. V., Clemmensen, I. H. \& Pihl, J. The Danish Cancer Registry-history, content, quality and use. Dan. Med Bull. 44, 535-539 (1997).
34. Sundhedsdatastyrelsen. Nye Kræfttilfælde i Danmark i 2016. Cancerregisteret. (2017). https://sundhedsdatastyrelsen.dk/da/tal-og-analyser/analyser-og-rapporter/ sygdomme/kraeft-_-cancerregisteret.

35. Greenland, S. R. K., Lash, T. L. in Modern Epidemiology. 3rd edn. p. 55-56 (eds. Rothman K. J., Greenland S., Lash T. L.) (Lippincott Williams \& Wilkins, Philadelphia, 2008).

36. Satagopan, J. M., Ben-Porat, L., Berwick, M., Robson, M., Kutler, D. \& Auerbach, A. D. A note on competing risks in survival data analysis. Br. J. Cancer 91, 1229-1235 (2004).

37. Breslow, N. E. \& Day, N. E. Statistical methods in cancer research. Volume II-The design and analysis of cohort studies. IARC Sci. Publ. 82, 65-71 (1987).

38. Venkatraman, V., Lee, L. \& Nagarajan, D. V. Lymphoma and malignant vasovagal syndrome. Br. J. Haematol. 130, 323 (2005).

39. Ballantyne, F. 3rd, VanderArk, C. R. \& Hilick, M. Carotid sinus syncope and cervical lymphoma. Wis. Med. J. 74, 91-92 (1975).

40. Dubrava, J., Drgona, L. \& Kadlecik, R. An unusual cause of recurrent syncope: Mediastinal lymphoma diagnosed with transesophageal echocardiography. Eur. J. Intern. Med. 16, 204-206 (2005).

41. Lichtman, M. A. \& Rowe, J. M. Hyperleukocytic leukemias: rheological, clinical, and therapeutic considerations. Blood 60, 279-283 (1982).

42. Oppenheimer, $\mathrm{S}$. The anatomy and physiology of cortical mechanisms of cardiac control. Stroke 24(12 Suppl), I3-15 (1993).

43. Parvizi, J. \& Damasio, A. Consciousness and the brainstem. Cognition 79, 135-160 (2001).

44. Christensen, T. D., Spindler, K. L., Palshof, J. A. \& Nielsen, D. L. Systematic review: brain metastases from colorectal cancer-Incidence and patient characteristics. BMC Cancer 16, 260 (2016).

45. Riihimaki, M., Hemminki, A., Sundquist, J. \& Hemminki, K. Patterns of metastasis in colon and rectal cancer. Sci. Rep. 6, 29765 (2016).

46. Badireddy M. B. K. Chronic anemia StatPearls(Internet). (2019). https://www.ncbi. nlm.nih.gov/books/NBK534803/.

47. Busti, F., Marchi, G., Ugolini, S., Castagna, A. \& Girelli, D. Anemia and iron deficiency in cancer patients: role of iron replacement therapy. Pharmaceuticals (Basel). 11, 1-14 (2018).

48. Schiavone, A., Biasi, M. T., Buonomo, C., Nozzoli, C., Roca, M. E., Sambati, R. et al. Micturition syncopes. Funct. Neurol. 6, 305-308 (1991).

49. Walker, H. K. in Clinical Methods: The History, Physical, and Laboratory Examinations (eds. Walker H. K., Hall W. D., Hurst J. W.) Chapter 12 (Boston, 1990).

50. Abdol Razak, N. B., Jones, G., Bhandari, M., Berndt, M. C., Metharom, P. Cancerassociated thrombosis: an overview of mechanisms, risk factors, and treatment. Cancers (Basel) 10, 1-21 (2018).

51. Sorensen, H. T., Mellemkjaer, L., Steffensen, F. H., Olsen, J. H. \& Nielsen, G. L. The risk of a diagnosis of cancer after primary deep venous thrombosis or pulmonary embolism. N. Engl. J. Med. 338, 1169-1173 (1998). 